\title{
The relationship between lipid metabolism and the level of albuminuria with single nucleotide polymorphism - 204a>c [rs 3808607] cyp7a1 gene in patients with type 2 diabetes mellitus and diabetic nephropathy
}

\author{
Nadiia Demihova ${ }^{1, \bowtie}$, Cherkashyna Lidiya ${ }^{2}$, Olha Chernatska ${ }^{1}$, Tetyana Mazur ${ }^{1}$, \\ Tetyana Aleksakhina ${ }^{1}$, Oleksii Demikhov ${ }^{1}$ \\ ${ }^{1}$ Sumy State University, Department of Family Medicine, Sumy, Ukraine \\ ${ }^{2}$ Kharkiv Medical Academy of Postgraduate Education, Kharkiv, Ukraine
}

\begin{tabular}{rrr}
\hline received: & June 26, $2019 \quad$ accepted: & August 15, 2019 \\
& available online: & October 21, 2019
\end{tabular}

\begin{abstract}
Background and aims. The purpose of our study was to determine the features of diabetic nephropathy, to identify the relationship between the level of albumin excretion, urine and lipid profile, genotype variants of the CYP7A1 gene in people with type 2 diabetes and diabetic nephropathy. Material and methods. Patients were divided into three groups. Normoalbinuria was detected in group I, and II - microalbuminuria, and III macroalbuminuria. Determination of albumin to creatinine ratio was more accurate, although more expensive method. We examined single nucleotide polymorphism -204A>C [rs 3808607] of the promoter region of the CYP7A1 gene. Results. It was established that homozygotes by the major allele with genotype AA had lower values of albuminuria, atherogenic lipoproteins, total cholesterol, triglycerides and higher levels of antiatherogenic lipoproteins than patients with $A C$ and $C C$ genotypes. Conclusion. The CC genotype was most unfavorable in the prognostic plan, since homozygotes for this minor allele were characterized by higher values of albuminuria, total cholesterol, triglycerides, and lower values of high-density lipoprotein
\end{abstract}

key words: type 2 diabetes mellitus, albuminuria, diabetic nephropathy, CYP7A1.

\section{Background and aims}

Today, diabetes mellitus (DM) plays a significant role in the development of nephropathy and the formation of chronic kidney disease (CKD) [1]. Approximately 30\% of patients with diabetes confirmed nephropathy $[\underline{2,3}]$.

The earliest indicator of the development of diabetic nephropathy (DN) is microalbuminuria
[4], which is also considered a risk factor for the development of cardiovascular complications [ $\underline{5}-$ 7].

$\mathrm{DM}$ is a specific defeat of the kidneys with diabetes, which is characterized by glomerular sclerosis and interstitial, which leads to a gradual loss of renal function.

Hyperglycemia is a major metabolic initiator of development of diabetic kidney damage. Mechanisms of nephrotoxic action of 
hyperglycemia include non-enzymatic glycosylation of proteins of renal membranes, as a result their structure and function is changes; direct toxic effect of glucose on the renal tissue, which leads to activation of the protein kinase $\mathrm{C}$ enzyme and increased renal vascular permeability; the activation of peroxidation of lipids, resulting in the formation of a large number of free radicals of cytotoxic action [8]. Direct damage to the endothelium of the vessels results in an increase in the glomerular barrier permeability for a fine-dispersed, highly selective, albumin-protein fraction. Since the kidneys are the organ with the highest concentration of arterioles in the body, the systemic defeat of the endothelium is manifested by a phenomenon of albuminuria.

Hyperlipidemia is another metabolic progression factor of DN. Oxidized low density lipoproteins penetrate the damaged endothelium of the capillaries of the renal glomeruli, admiring the mesangial cells with the formation of foamy cells around which collagen fibers are formed, and glomerulosclerosis develops [9,10].

Determining of albumin to creatinine ratio in urine is a more accurate method than the definition of albuminuria, since the level of creatinine excreted in urine depends on age, sex, body mass index [11].

Glucose can interact with a variety of proteins and form additional glycogen compounds that contribute to endothelial dysfunction, the development of the atherosclerotic process, vascular thrombosis [12-14]. One of them is glycosylated hemoglobin (HbA1c), which is accumulated inside the erythrocytes and is maintained throughout its entire functioning. Since the half-cycle of erythrocyte circulation in the bloodstream is 60 days, the concentration of HbA1c reflects the patient's glycemia in 60-90 days prior to the study [15]. Considering the life expectancy of erythrocyte, which is 120 days, it is expedient to determine the level of HbAlc once every three or four months $[\underline{2,3}]$.

Releasing chemotactic cytokines and adhesion molecules on its inner surface promotes the adhesion of circulating mononuclear cells to the vascular wall. Inflammatory mediators activate smooth muscle cells, causing their proliferation and migration under the intima of blood vessels.

It is in the presence of dyslipidemia that monocytes, which are contained in the vascular wall, react with cholesterol of low-density lipoprotein (LDL) and turn into macrophages containing lipids, which is the basis of the atherosclerotic process. Macrophages decree metal proteases and cathepsins by destabilizing the fibrous capsule of the atherosclerotic plaque, which can lead to rupture of the atherosclerotic plaque and release of the tissue factor that causes thrombosis, occlusion of coronary vessels, and acute myocardial infarction $[\underline{16}, \underline{17]}$.

Insulin activates the synthesis of free fatty acids (FA) and triglycerides (TG), reduces the rate of $\beta$-oxidation of $\mathrm{FA}$ in the liver, which leads to deposition in the liver TG. This leads to the development of insulin resistance (IR) and subsequent deposition of fat in the liver. Glucose metabolism may be associated with bile acid metabolism [18]. Cholesterol 7-alphahydroxylase (CYP7A1) is the first enzyme in a series of cholesterol transformations, which results in the synthesis of bile acids [19].

CYP7A1 belongs to a large family of cytochromes $\mathrm{p} 450$. The gene encoding the CYP7A1 enzyme is located on the 8q11-12 chromosome and consists of 6 exons and 5 introns. Genetic variants of this gene have an effect on levels of LDL and TG [20]. The polymorphism -204A> C [rs 3808607] of the gene CYP7A1 is located on the promoter region $[21,22]$. A correlation was found between the 
lipid profile of the blood and the given polymorphism [20,23].

The purpose of the study was the determination of the indices of blood lipid profile, single nucleotide polymorphism-204A> C [rs 3808607] of the CYP7A1 gene, depending on the level of albuminuria in individuals with type 2 diabetes and diabetic nephropathy.

\section{Materials and methods}

Sixty patients with type 2 diabetes and diabetic nephropathy were examined. The diagnosis of diabetes was established if the blood glucose content in the onset of blood was greater than $6.1 \mathrm{mmol} / \mathrm{l}$, with a pre-starvation of 12 hours and more than $11.1 \mathrm{mmol} / \mathrm{L}$ two hours after loading with glucose $(75 \mathrm{~g})$. The analysis was repeated 2-3 times on other days. Diabetic nephropathy has been established if the GFR $>90$ $\mathrm{ml} / \mathrm{min}$.

The patients were divided into groups depending on the level of albumin excreted in the urine, determined in a one-time morning portion of the urine. The determination of albuminuria was carried out by the immunoassay method on a semi-automatic analyzer BA-88 (China).

In patients of the first (I) group, normalbumbumurium was detected, at the level of secreted protein $<20 \mathrm{mg} / 1$, the second microalbuminuria (20-200 mg / ), and the third macroalbuminuria (> $200 \mathrm{mg} / \mathrm{1}$ ).

The mean age of patients in the I group was $(55.44 \pm 0.23)$ years, II $-(64.92 \pm 0.31)$ years, $t$ $=24.56 ; \mathrm{p}<0.001$, III $-(60.37 \pm 0.28)$ years, $\mathrm{t}=$ 13.6; $\mathrm{p}<0.001$.

The level of HbA1c in serum was determined by high-sensitivity ion-exchange chromatography using the automatic analyzer D10 and BIO-RAD (USA) reagents.

In all patients, the single-nucleotide polymorphism -204A>C [rs 3808607] of the promoter region of the gene CYP7A1 expressing the enzyme cholesterol $7 \alpha$-hydroxylase has been studied. We identified three genotypes: AA, AC, CC. The lipid blood spectrum for each of the genotypes was investigated.

The determination of the mononucleotide polymorphism -204A>C [rs 3808607] of the CYP7A1 gene was carried out using a polymerase chain reaction method followed by an analysis of the length of the restriction fragments.

All patients were tested for lipid profile and an index of atherogenicity was calculated. Biochemical analysis of blood was determined such indicators of the lipid spectrum of blood as total cholesterol (TC), TG and high density lipoprotein (HDL), LDL, and very low density lipoprotein (VLDL).

LDL cholesterol was calculated by the formula:

$$
\mathrm{LDL}=\mathrm{TC}-(\mathrm{HDL}+\mathrm{TG} / 2,2)
$$

If the TG content exceeded $4.5 \mathrm{mmol} / \mathrm{L}$, then LDL cholesterol was calculated using the Friedwald formula:

$$
\mathrm{LDL}=\mathrm{TC}-\mathrm{HDL}-0,45 \times \mathrm{TG}
$$

LPDL $=$ TG: 2,18 .

The index of atherogenicity was also calculated. The coefficient of atherogenicity (CA) is calculated very simply: $\mathrm{CA}=($ total cholesterol - HDL) / HDL.

The obtained results were processed by the method of variation statistics using the programs Microsoft Exel 2007 and statistics for Windows 6.0 using Student's criterion. The average arithmetic mean value $(\mathrm{M})$, the mean arithmetic mean error $(\mathrm{m})$ was calculated.

\section{Results}

After determining the amount of urineexcreted protein, it was found that 44 patients 
(73.33\%) had normoalbuminuria, 8 (13.33\%) microalbuminuria, and $8(13.33 \%)$ - macroalbuminuria. Proteinuria was not diagnosed in any patient. Since the amount of creatinine excreted in urine may be different and depend on body weight, age of patients, we decided to determine the ratio of microalbumin to creatinine in urine, after which normoalbuminuria was detected in 41 patients $(68.33 \%)$, microalbuminuria at 9 (15.0\%), macroalbuminuria - in $9(15.0 \%)$ proteinuria - in $1(1.66 \%)$. Possibly, in the past, the value of the protein isolated from the urine was greater but decreased in the result of the nephroprotective effect of antihypertensive drugs that patients had taken over the years.

In 57 patients $(95.0 \%)$, the level of protein isolated from urine, determined after the determination of albuminuria and the ratio of albumin to creatinine, coincided, and in $3(5.0 \%)$ was different.

Thus, a more accurate method with a difference of $5.0 \%$ for the study of kidney function in type 2 diabetes is to determine the ratio of albumin to creatinine.

Duration of diabetes in people with normoalbuminuria was $(5.43 \pm 0.05)$ years, with microalbuminuria - $(10.22 \pm 0.22)$ years, $t$ $=21,23 ; \mathrm{p}<0.001$, with macroalbuminuria $-(14.3$ \pm 0.37 years) years, $t=23.78 ; p<0.001$. It has been shown that the duration of the disease on type 2 diabetes correlates with the level of albuminuria.

For individuals of group I, the level of $\mathrm{HbAlc}$ was $(6.21 \pm 0.23) \%$, for II $-(7.31 \pm 0.22) \%, t=$ $3.46 ; \mathrm{p}<0.01$, for III $-(7.65 \pm$ $0.45) \%, t=2.85 ; \mathrm{p}<0.01$ Consequently, a direct proportional relationship was found between the degree of albuminuria and the level of HbAlc.

After determining the lipid profile of the blood, a direct proportional relationship was found between the degree of albuminuria and the level of Total Cholesterol (TC), TG, LDL, LDL, and inversely proportional dependence on HDL.

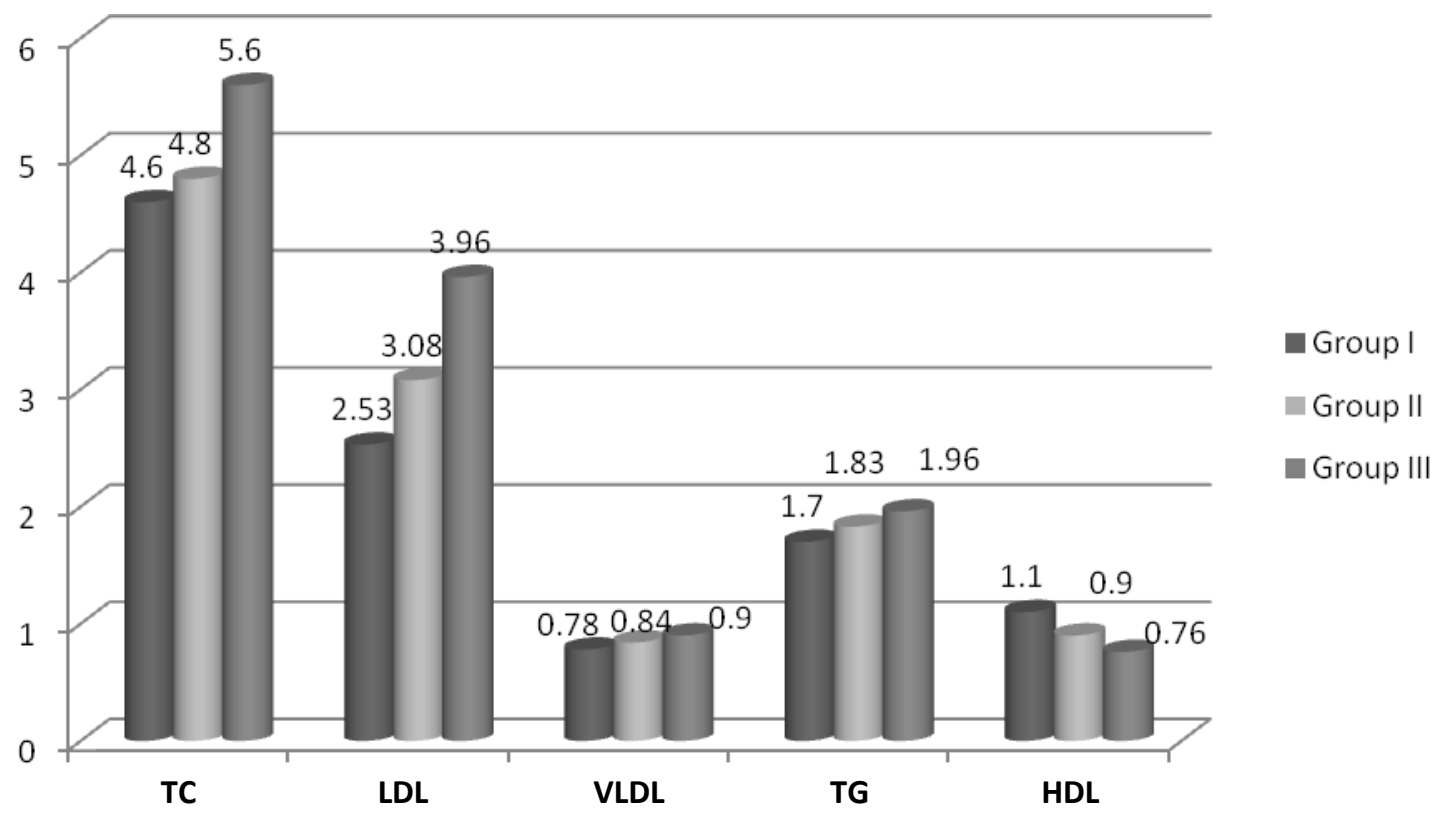

Fig. 1. Dynamics of lipid profile of blood depending on the level of albuminuria in patients with type 2 diabetes. 


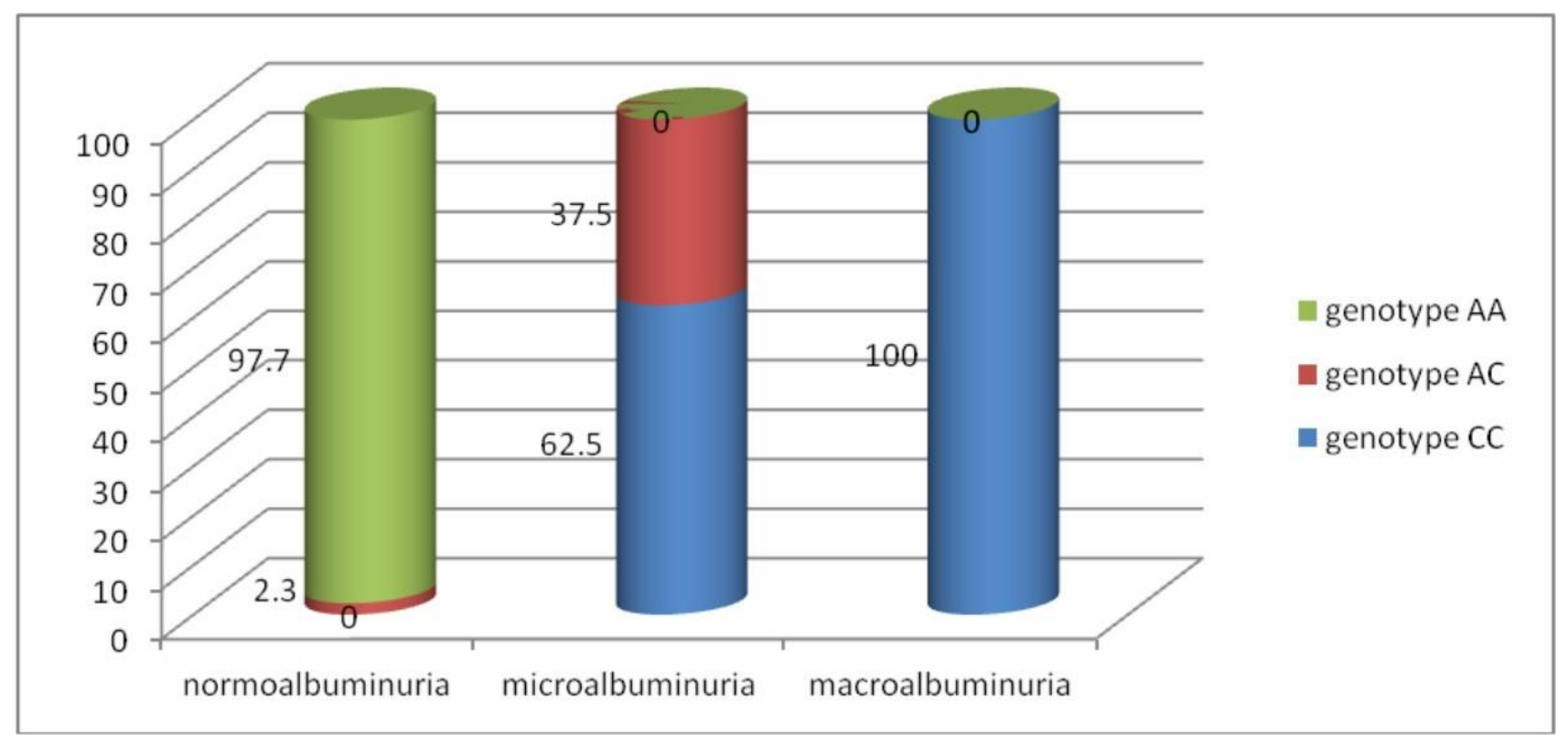

Fig. 2. Frequency of allelic variants of the gene of CYP7A1 for polymorphism $-204 A>C$.

In the 1st, 2nd, 3rd group, the level of TC was $(4,4 \pm 0,04) \mathrm{mmol} / 1,(4,8 \pm 0,06) \mathrm{mmol} / 1$, $\mathrm{t}=6,57, \mathrm{p}<0,001,(5,6 \pm 0.23) \mathrm{mmol} / 1, \mathrm{t}=$ $3.36, \mathrm{p}<0.01, \mathrm{LDL}-(2.53 \pm 0.5) \mathrm{mmol} / \mathrm{l},(3.08$ $\pm 0.05) \mathrm{mmol} / \mathrm{l}, \mathrm{t}=4.7, \mathrm{p}<0.001,(3.96 \pm$ $0.35), \mathrm{t}=2.34, \mathrm{p}<0.05 ; \mathrm{LPDL}-(0.78 \pm 0.05)$ $\mathrm{mmol} / \mathrm{L},(0.84 \pm 0.02) \mathrm{mmol} / \mathrm{L}, \mathrm{t}=4.9, \mathrm{p}$ $<0.001,(0.9 \pm 0.01) \mathrm{mmol} / \mathrm{L}, \mathrm{t}=2.35, \mathrm{p}<0.05$, $\mathrm{HDL}-(1.1 \pm 0.04) \mathrm{mmol} / 1,(0.9 \pm 0.01) \mathrm{mmol} /$ $1, \mathrm{t}=4.85, \mathrm{p}<0.001(0.76 \pm 0.03) \mathrm{mmol} / 1, \mathrm{t}=$ $6.8, \mathrm{p}<0.001, \mathrm{TG}-(1.7 \pm 0.04) \mathrm{mmol} / \mathrm{L},(1.83$ $\pm 0.01) \mathrm{mmol} / \mathrm{L}, \mathrm{t}=3.15, \mathrm{p}<0.01,(1.96 \pm 0.05)$ $\mathrm{mmol} / \mathrm{l}, \mathrm{t}=4.06, \mathrm{p}<0.001$ (Figure 1).
In persons with type 2 diabetes and $\mathrm{AG}$ of the third stage, 43 (71.66\%) persons of the AA genotype met, in the AC - 4 (6.66\%), CC - in 13 (21.66\%) persons. Consequently, the major allele should be considered allele A, and minor - allele C. In addition, among 44 patients with normoalbuminuria, the genotype AA was confirmed in $43(97.73 \%)$, in the $\mathrm{AC}$ - in 1 (2.27\%). In people with microalbuminuria, the genotype of the AC was detected in $3(37.5 \%)$, $\mathrm{CC}$ - in $5(62.5 \%)$ patients. All of the subjects who had macroalbuminuria determined the $\mathrm{CC}$ genotype (Figure 2).

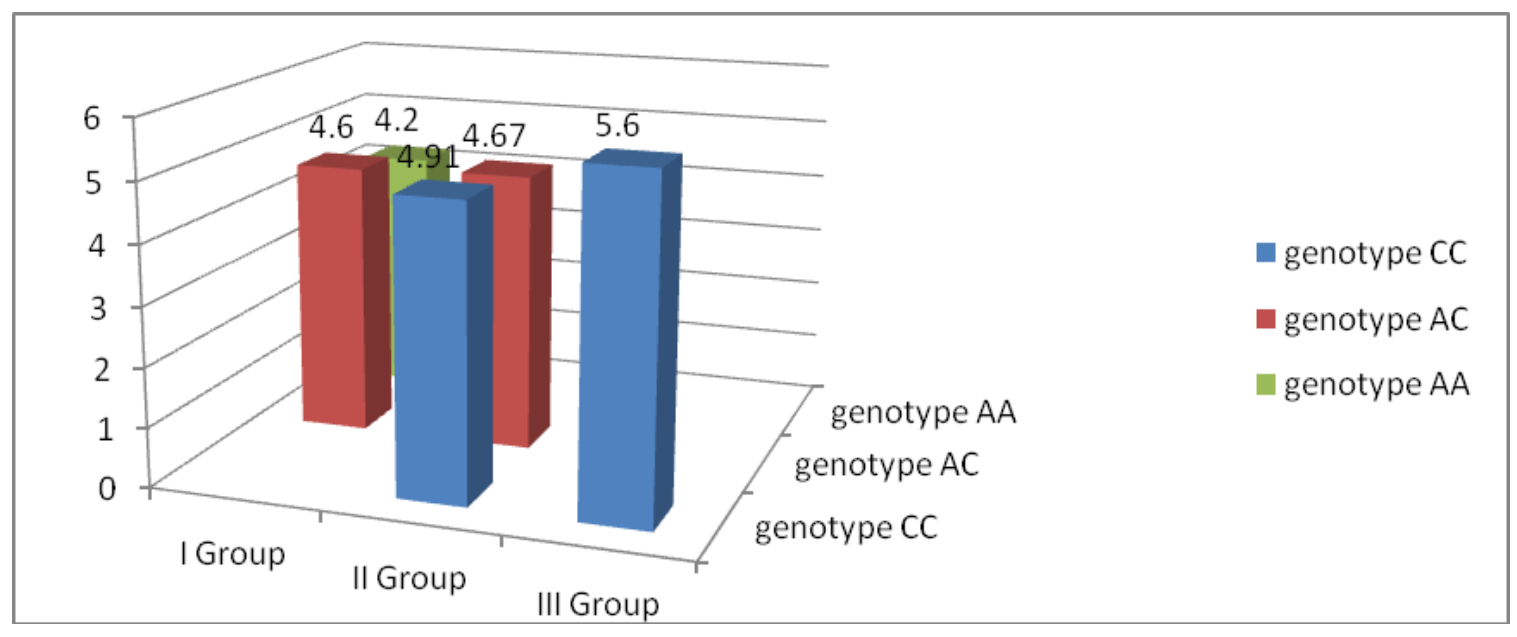

Fig. 3. The level of TC with different genotypes of CYP7A1. 


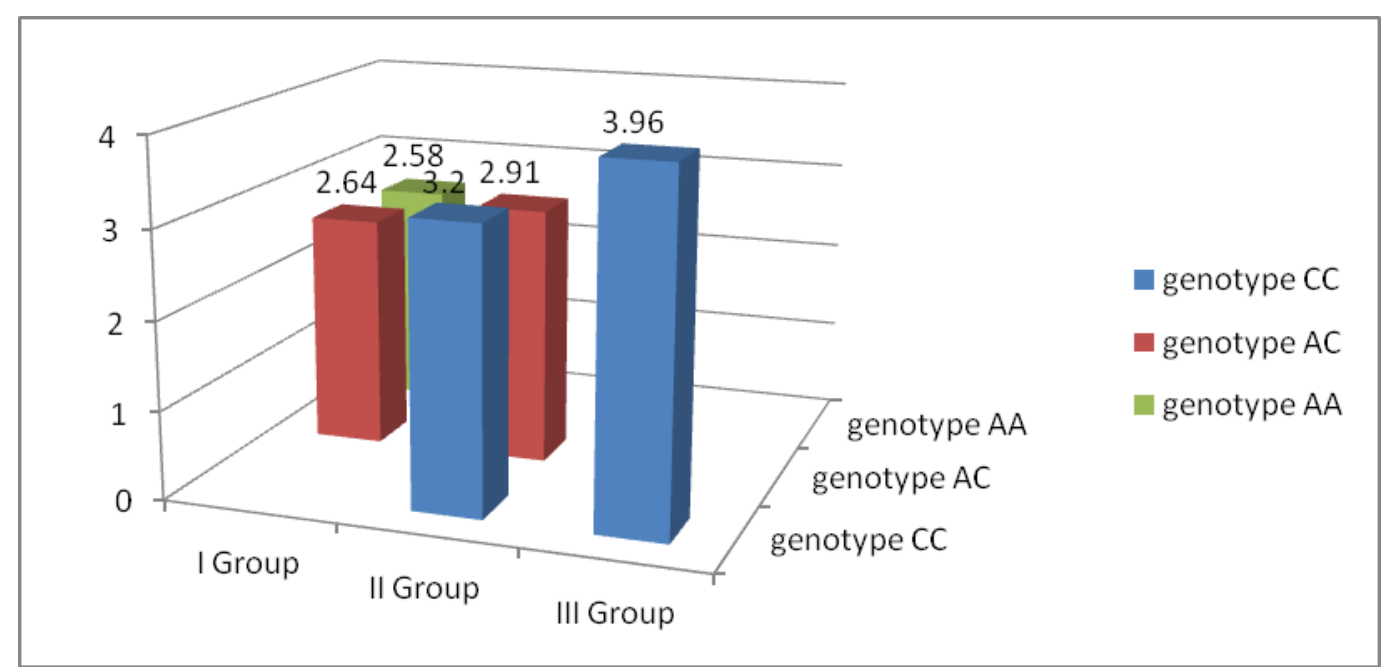

Fig. 4. The level of $L D L$ in different genotypes is CYP7AI

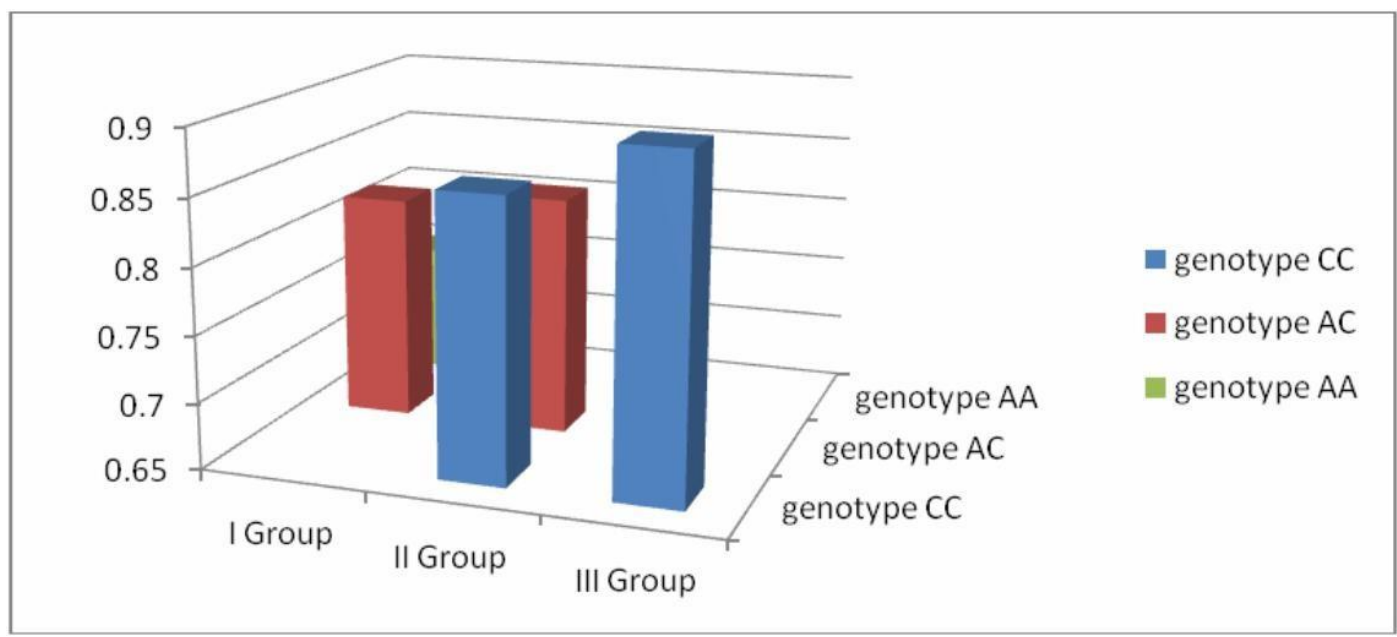

Fig. 5. VLDL level at different genotypes of CYP7A1

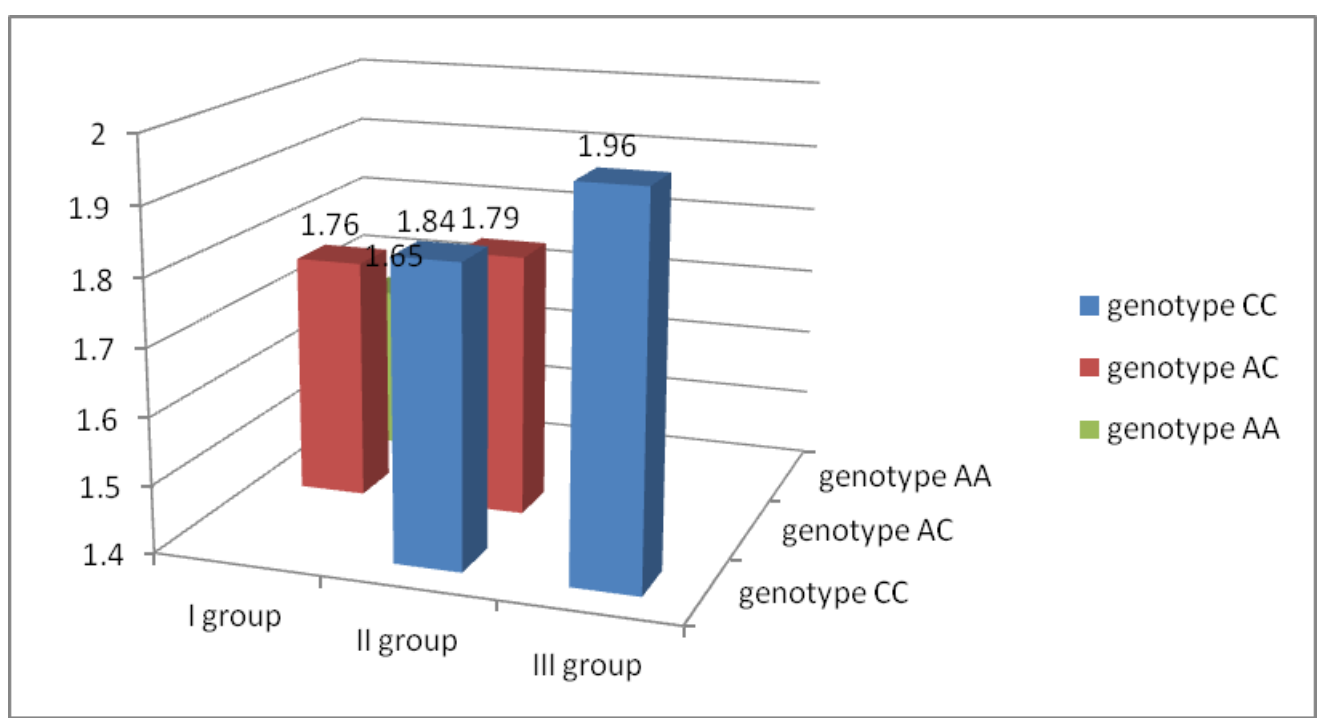

Fig. 6. TG level with different genotypes of CYP7A1 


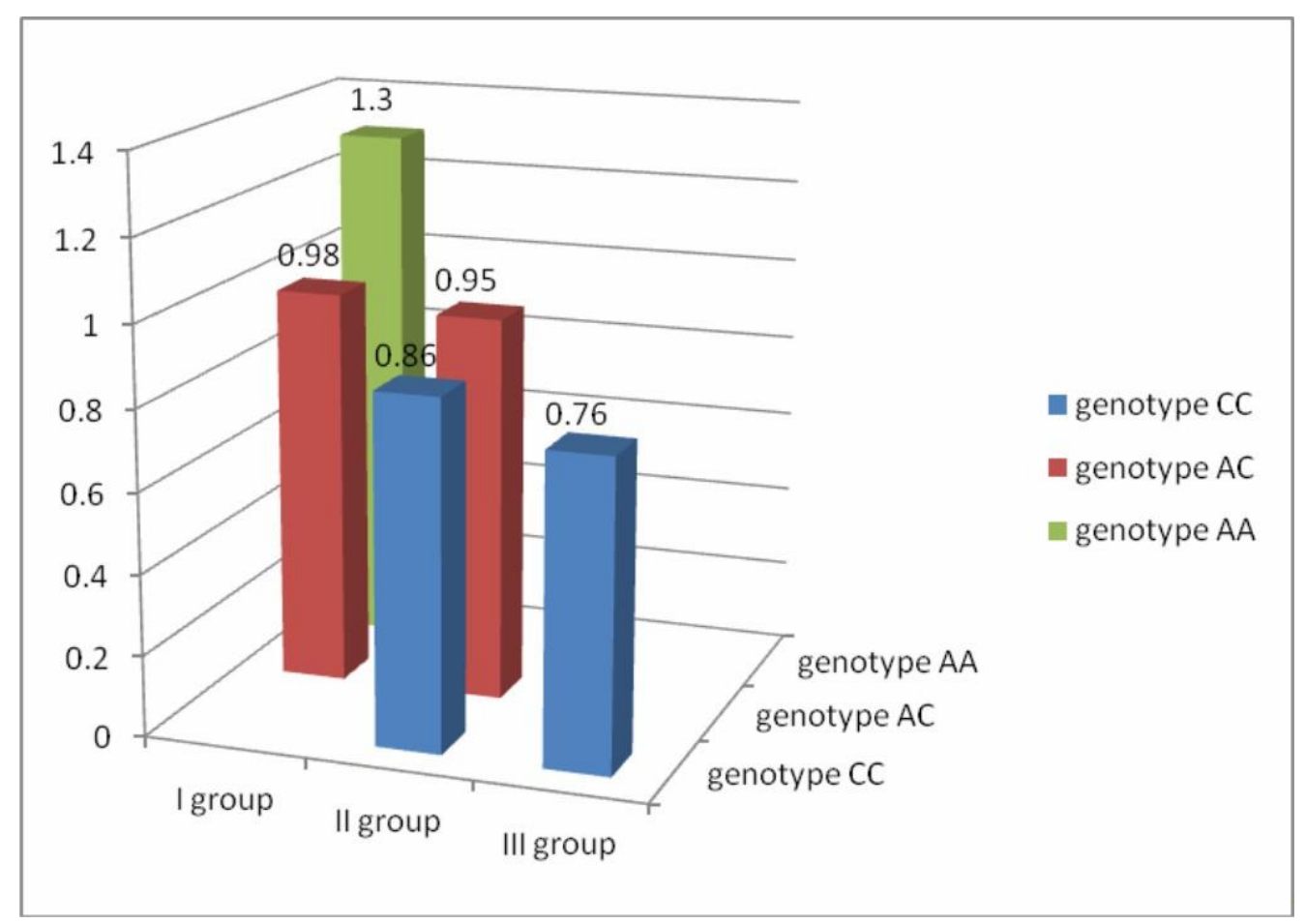

Fig. 7. The level of high-density lipoprotein with different genotypes of CYP7A1

Specific features of the blood lipid profile were also determined, depending on the genotypes AA, AC and CC.

It was found that in homozygotes with AAgenotype the levels of LDL, LDL, TG, TC were lower and HDL - higher. In the heterozygotes with the AC-genotype, the values of atherogenic lipoproteins, TG, and TC were higher, and the lower ones were antiatherogenic compared with those who had the AA-genotype. In the homozygote for the minor allele (CC-genotype), the values of LDL, VLDL, TG, and TC were the largest, and HDL were the smallest.

\section{Conclusions}

Determination of the ratio of albumin to creatinine in a one-morning portion of urine is more accurate, more expensive marker of DN than the counting of only albuminuria.

There is a direct proportional relationship between the level of HbA1c and the duration of type 2 diabetes, diabetic nephropathy.

The degree of albuminuria is positively correlated with the level of LDL, VLDL, TG, TC.

CC-genotype-204A> C [rs 3808607] of the promoter region of the CYP7A1 gene is the most adverse in the prognostic plan and is associated with a higher level of albuminuria, HbA1c, atherogenic lipoproteins, and lower antiatherogenic lipoproteins.

\section{REFERENCES}

1. Netchessova T. Results of NIKA STUDY Journal of hypertension 29 (Suppl. A): 277-279, 2011

2. Baharivand N, Zarghami N, Panahi $\mathbf{F}$ et al. Relationship between vitreous and serum vascular endothelial growth factor levels, control of diabetes and microalbuminuria in proliferative diabetic retinopathy Clin Ophthalmol 6: 185-191, 2012

3. Kumar S, Aneja GK, Trivedi A et al. Correlation of diabetic nephropathy and $\mathrm{HbA} 1 \mathrm{C}$ in newly 
diagnosed type 2 diabetic patients of western UP. IJSRP 4(12): 1-4, 2014

4. Taslıpınar A, Yaman H, Yılmaz MI et al. The relationship between inflammation, endothelial dysfunction and proteinuria in patients with diabetic nephropathy Scand J Clin Lab Invest 71(7): 606-612, 2011

5. Gohda T, Niewczas MA, Ficociello LH et al. Circulating TNF receptors 1 and 2 predict stage 3 CKD in type 1 diabetes J Am Soc Nephrol 23(3): 516-524, 2012

6. Marushchak M, Krynytska I, Mikolenko A et al. Chronic heart failure causes osteopathy or is osteopathy a factor in development of chronic heart failure? Asian Journal of Pharmaceutical and Clinical Research 11(1): 111-115, 2018

7. Wu HY, Huang JW, Peng YS et al. Microalbuminuria screening for detecting chronic kidney disease in the general population Renal Failure 35(5): 607614,2013

8. Guzyk MM, Dyakun KO, Yanytska LV et al. Inhibitors of Poly (ADP-Ribose) Polymerase-1 as Agents Providing Correction of Brain Dysfunctions Induced by Experimental Diabetes Neurophysiology 49(3): 183-193, 2017

9. Krynytska I, Marushchak M. The Indices of Nitric Oxide System in Rats with Carrageenan-Induced Enterocolitis Combined with Diabetes Mellitus Rom J Diab Nutr Metab Dis 25(3): 283-288, 2018

10. Prykhodko OA, Gulaya VI, Yarmolenko OS et al. Microscopic changes in the organs of rats under conditions of general dehydration of the organism Azerbaijan Medical Journal 4: 95-100, 2016

11. Ismail-Beigi F, CravenTE, O'Connor PJ et al. Combined intensive blood pressure and glycemic control does not produce an additive benefit on microvascular outcomes in type 2 diabetic patients Kidney Int 81(6): 586594,2012

12. Demikhova $\mathbf{N}$, Chernatska $\mathbf{O}$, Mazur $\mathbf{T}$ et al. Markers of cardiovascular complications in patients with type 2 diabetes mellitus and arterial hypertension Bangladesh Journal of Medical Science 17(2): 319-322, 2018

13. Zhao W, Katzmarzyk PT, Horswell R et al. Aggressive blood pressure control increases coronary heart disease risk among diabetic patients Diabetes Care 36: 3287-3296, 2013

14. Zhao W, Katzmarzyk PT, Horswell $\mathbf{R}$ et al. Blood pressure and stroke risk among diabetic patients. $J$ Cin Endocrinol Metab 98: 3653-3662, 2013

15. Kluczyk MB, Radziejewska I, Darewicz B et al. Glycosylation of proteins in healthy and pathological human renal tissues Folia Histocheml Cytobiol 50(4): 599604,2012

16. Rosendorff C, Lackland DT, Allison $M$ et al. Treatment of hypertension in patients with coronary artery disease J Am Coll Cardiol 65(18): 1998-2038, 2015

17. Chernatska O., Demikhova N. Improvement of treatment in persons with arterial hypertension and type 2 diabetes mellitus Georgian Med News 11(284): 47-51, 2018

18. Sun $W$, Zhang $D$, Wang $Z$ et al. Insulin resistance is associated with total bile acid level in type 2 diabetic and nondiabetic population Medicine (Baltimore) 95(10): 2778, 2016

19. Iwanicki $T$, Balcerzyk $A$, Niemiec $P$ et al. CYP7A1 gene polymorphism located in the 5 upstream region modifies the risk of coronary artery disease Hindawi Publishing Corporation 2015: 1-6, 2015

20. Krishnamurthy $K$, Vedam $K$, Kanagasabai $R$, Druhan LJ, Ilangovan G. Heat shock factor-1 knockout induces multidrug resistance gene, MDR1b, and enhances P-glycoprotein (ABCB1)-based drug extrusion in the heart Proc Natl Acad Sci U S A 109(23): 9023-9028, 2012

21. Qrafli M, Amar Y, Bourkadi J et al. The CYP7A1 gene rs3808607 variant is associated with susceptibility of tuberculosis in Moroccan population. Pan Afr Med J 18: 2-15, 2014

22. Zhaldak DA, Melekhovets OK., Orlovskyi VF CYP7A1 gene polymorphism and the characteristics of dyslipidemias in patients with nonalcoholic fatty liver disease concurrent with hypothyroidism Ter Arkh 89(10): $62-65,2017$

23. Cai Q, Wang ZQ, CaiQ, Li C, Chen E-Z, Jiang Z-Y. Relationship between CYP7A1 -204A > C polymorphism with gallbladder stone disease and serum lipid levels: a meta-analysis. Lipids in Health and Disease 13: 126,2014 